The International Journal of Engineering and Science (IJES)

|| Volume || 6 || Issue || 6 || Pages || PP 43-49 || 2017 ||

ISSN (e): $2319-1813$ ISSN (p): $2319-1805$

\title{
Gating and Residential Segregation. A Case of Indonesia
}

\author{
Salmina W Ginting ${ }^{1}$, Endang Titi Sunarti Darjosanjoto ${ }^{2}$, Haryo Sulistyarso ${ }^{3}$ \\ ${ }^{I}$ PhD Program. Department of Architecture, Institut Teknologi Sepuluh Nopember (ITS), Indonesia \\ ${ }^{2}$ Professor of Urban Morphology, Department of Architecture, Institut Teknologi Sepuluh Nopember (ITS), \\ Indonesia \\ ${ }^{3}$ Senior Lecturer, Department of Architecture, Institut Teknologi Sepuluh Nopember (ITS), Indonesia
}

\begin{abstract}
Gating is an effort to control access to the settlement, especially to unwanted social contact. Gating usually manifested on spatial elements such as gate, wall, fence, security check point, swing up portal, etc. at their main entrance. The term gating then relates to gated community as a modern-exclusive residential which is in some cases, reinforce both spatial and social segregation. This paper analyzes gating and its relation to segregation from spatial point of view. The role and function of wall, gate, and border is analyzed to define whether it is a manifestation of security or a matter of life style. This paper concludes gating as both security and life style aspect, and gives influence to semi-restricted segregation.
\end{abstract}

Keywords: gating, residential, spatial, segregation.

Date of Submission: 14 May 2017 Date of Accepted: 22 June 2017

\section{INTRODUCTION}

The most common perception of gating is that it represents social exclusion [1]. Or, as Low [2] writes, it is a description of unreality of life. Sennett [3] writes gating is one way of limiting public togetherness by controlling social contact. Atkinson and Flint [4] write gating is a way to limit with whom to meet and speak for example, only with people like us. The concept of gating has existed since a long time, ranging from fortress city due to Western colonialism to Forbidden City in China. From the Dutch fortress at the Indonesian coastal cities to the kinship community in Bali. In urban studies field, gating in housing development is understood as part of enclave urbanism [5], splintering urbanism [6], architecture of fear [7], and city of walls [8]. Gating then related to the term gated community (or GC) that indicates housing with a gate or fence that limit public access [1].

Gated community often discussed as a form of socio-economic inequality, however also discussed in relation to lifestyle and security aspects. Blakely and Snyder's [9] research, which is still a reference to date, shows that there are 3 (three) types of gated communities in the United States: lifestyle, prestige, and security. It is interesting to see how Leisch [10], fifteen years ago, doing similar research in the Jakarta Metropolitan Region and finding that gated communities in Jakarta are spatially duplicating GCs in the United States, from architectural styles into the use of security features. But unlike the findings of Blakely and Snyder, Leisch states, in Indonesia, the reason for choice staying in GC is security aspect, which is far more prominent than lifestyle and prestige. Gating is further cited as the culprit of social and spatial segregation both. Here, segregation is defined as spatial dominance by a particular group, in terms of income levels, religion, race, ethnicity, etc., which causes other groups to experience accessibility problems, marginalization and isolation [11].

Another opinion comes from Marcuse [12] who writes segregation related to border, not in term of theres IS or there IS NOT border. Segregation occurs when access to public spaces that should be universally accessible for all-including people outside of GC- becomes a little more restricted.

This paper discusses gating and its relation to segregation from a spatial point of view. Gating may be a manifestation of urban fear and urban crime in the form of closed and exclusive residential, offering a sense of security. Or, it may be a part of a modern lifestyle that emphasizes "image" and prestige. The paper will first describe how the configuration of spatial gating elements i.e. fences, gates, border elements, etc. speaks loud as a manifestation of the security aspect OR simply as modern lifestyle. Furthermore, gating is also analyzed in relation to segregation. Paper will take one GC named Pakuwon City in Surabaya, Indonesia, as a case study. 


\section{Gate, fence, and border}

\section{THEORITICAL REVIEW}

Ellin [13] writes gating is the way people get protective devices. People used to deliberately design cul-de-sac and minimize sidewalk or pedestrian lines. Now added fence and security guard complete with CCTV monitor. He writes: the lack of sidewalks and cul-de-sacs of the earliest suburban developments were protective devices, but gate our neighborhoods and installing guards or video monitors at the entryways "- p. 9. Later on, gating is identically connected with term gated community or GC which has special characters. GC is defined as a residential area with characters: 1) limited by a wall or fence; 2) have certain security systems such as CCTV, security officers, access cards, and so on; and 3) restrictions on access to public space [9][4][2][14]. Meanwhile Grant and Mittelsteadt [15] add gating as an attempt to control access, and to assert between "inside" and "outside". They wrote: a gated community is closed to general traffic by a gate across the primary access. The developments may be surrounded by fences, walls, or other natural barriers that further limit public access - p. 913-914. In Indonesia, as written by Leisch [10], most GCs in Jakarta are gated with certain security systems. He writes: most of the new land developments are gated with more or less effective security measures. There are residential areas surrounded by walls and fences but with an open gate and sometimes no security guards - $\mathrm{p}$. 343.

This theoretical study leads to the spatial aspect of gating which is wall, gate, and border. Sennett [3] writes the border as the limit is a social product and not a physical product, and that all boundaries are socially constructed. According to him, even invisible border can limit. For example a toll road that is straight on the edge of the city with no height dimensions such as city wall, is a border because making it difficult for people to cross over the road. This invisible border becomes the real border because it has split area into parts which is not connected. It is ironic because the road may be built for the purpose of connecting not separating.

Johnson et al [16] (2011) writes a border is not a fixed physical object. They write borders as "sum of social, cultural, and political processes, rather than simply as fixed lines" - p.61. Blakely and Snyder [9] note GC as a new form of fortified community that puts security and protection as the most important part of its development. Both authors agree GC is a refugee of urban problems such as congestion, pollution, urban crime, and urban fear. In Southeast Asia case, Leisch [10] concluded three important things about gating: 1) gating occurs because of the increasing number of rich people who want protection against himself and his property; 2) staying within the GC is a prestige symbol that shows a high level of modernity; and 3) especially in Indonesia, people from ethnic Chinese are always "different" and separated because of differences in welfare and religious as well. The Chinese are the most occupied GC especially in Indonesia.

Gating as security aspect is common in South America where criminal acts are prevalent in society. The spatial form of gating for security aspects is a fence of at least 2 meters height with tight guard. Gating is applied not only by the rich but almost by all layers of society, ranging from "golden prison" to the slum settlement called favelas [8] [17]. Here, gating influences segregation in generally fully restricted. Gating is more like a modern lifestyle if the level of restricted area is lower than gating for security. Gating as part of lifestyle is not fully restricted but semi-restricted. It is characterized by a fence which is generally not massive, the height is less than 2 meters, and the swing-up portal does not always combines with access card.

\section{Segregation}

Residential segregation is a situation where two separate groups live in different parts of the city [18]. They note that residential segregation does not occur as a result of a single process but rather of various forms of social and economic processes called "segregation". Firman [19] proves the phenomenon of spatial segregation in Jakarta Metropolitan Region by looking at three things: 1) polarization of upper class society in exclusive residential area; 2) the residential is walled and the spaces inside are segmented in several social classes where there is no interaction among classes; and 3) some residentials are managed by non-government private developers and implement regulations that prevent interaction and socialization with "outsiders" and therefore encourage segregation. Another study by Winarso et al [20] mentions the peri-urbanization process in the Jakarta Metropolitan Region has caused spatial segregation because the land in the peri-urban is built for the benefit of a group of upper class people only.

Sennet [3] writes two important things about the border that determine the nature of segregation. First, the border is not an end either an edge. Border, according to Sennet, is not an edge as a symbol of the final end, marked by, for example, a wall or a statue of the lion that keeping out. Gating becomes a segregated if it limits accessibility to functions that are supposed to be public [12]. For example, if gating limits access to roads, parks, play areas, and other public spaces, then it is called segregation. However, if gating limits only in a private area, such as a house, then it should not be considered segregated. This is because as Bickford [14] states, home is a private domain that is entitled to have their own rules. 
This paper explains residential segregation by analyzing location and design of gating element such as gate, wall, and border and all its security features. These elements will define whether it caused by security aspect or part of modern lifestyle. By using term and definition of Marcuse [11] and Bickford [13], the paper analyses if gating happens to be a segregation process.

\section{METHODS}

This paper reviews segregation from a spatial point of view, i.e. how the location, position, and design of the gating elements influence segregation. The hypothesis is built on the basic assumption that there is a relationship between spatial aspects and social phenomenon. That is, space in the broadest sense can logically explain the social aspects of everyday life, including segregation [21]. Ginting et al [22] also prove that architecture contributes to color in social life, for example housing design can encourage or discourage segregation.

The configuration of residential spaces and buildings, how they are designed and organized, greatly affects segregation, both among residents in one GC or residents and non-residents of GC. One GC in Surabaya, Indonesia, namely Pakuwon City, was selected as a case study. In contrast to the assumption of "western" knowledge of GC as exclusive enclave which is not publicly accessible, Pakuwon City is relatively open and accessible. This GC uniqueness will be discussed in more detail on how the position, location, and design of gating elements indicate the reason people live in the GC. Furthermore, these elements-how they are designed and configured-will explain their effects on segregation process as well. Spatial elements of gating to be discussed are wall, gate, and border. The method of data collection and analysis will be conducted as Table 1 below.

Table 1. Data Collection and Analysis

\begin{tabular}{|c|c|c|}
\hline Gated Community as & Indicators & Analysis of Segregation \\
\hline $\begin{array}{l}\text { 1. Manifestation of security } \\
\text { aspect (fear of urban } \\
\text { crime and urban fear) }\end{array}$ & $\begin{array}{l}\text { - Massive gate or fence } \\
\text { - Height of gate and fence } \\
\text { is more than } 2 \text { meter } \\
\text { - Mostly for protection of } \\
\text { belongings and } \\
\text { avoidance of unwanted } \\
\text { contact }\end{array}$ & \multirow{2}{*}{$\begin{array}{l}\text { Gating becomes } \\
\text { segregation if it limits } \\
\text { accessibility to } \\
\text { functions that are } \\
\text { supposed to be public } \\
\text { (Marcuse, 1997). For } \\
\text { example, if gating limits } \\
\text { access to roads, parks, } \\
\text { play areas, and other } \\
\text { public spaces, then it is } \\
\text { called segregation }\end{array}$} \\
\hline $\begin{array}{l}\text { 2. A life style of modern- } \\
\text { high class of society }\end{array}$ & $\begin{array}{l}\text { - Simple gate for signing } \\
\text { the territory } \\
\text { - Height } 1-2 \text { meter } \\
\text { - More open and more } \\
\text { accessible }\end{array}$ & \\
\hline
\end{tabular}

\section{Gating and residential segregation in Indonesia.}

\section{RESULT AND DISCUSSION}

In Indonesia, large-scale residential and new town began to be built in Jakarta in the 1950s. The first newly built city was Kebayoran Baru on the outskirts of Jakarta in the 1950s, then followed Pondok Indah in the 1970s. The construction of the new city took place very quickly and reached the number of 30 new cities throughout Jabodetabek in the 2000s. This new city has an area that varies between 500-6000 ha with various facilities in it such as hotels, office complexes, international schools, hospitals, and recreational facilities such as water parks, golf courses, and so forth as written in Rakodi and Firman [23]. Planning and residential design in Indonesia, as has been widely written, is the adoption of residential spatial forms in the United States and Europe. Not only in terms of style or style of architecture, but also in the residential naming. The forms of cul-de-sac, classical or modern architectural styles, and names such as Diamond Hill, Buena Vista clusters, Esplanade Park, and others reflect the reality of the social upper and middle class Indonesians leaning toward the "West" especially the United States. Although Indonesia has its own tradition of building residential complexes, for example in Bali, the now rampant residential is relatively non-reflective of the cultural heritage.

Past research that took the case in Indonesia, indicates that residential design that is all "Western" is more symbolic than functional. Homes and dwellings are designed not solely to fulfill the function of a safe and comfortable residence (security aspect), but are part of lifestyle and prestige [10][19]. For the case in Surabaya, Nas [24] wrote one of the oldest residences in Surabaya, namely Darmo Satelit as satellite town. He described the residential housing cluster equipped with guard posts and controlled entrances.

Dick [25] in a chapter discussing real estate developments in Surabaya writes the appearance of the Darmo Grande estate in western Surabaya is another form of social segregation. He wrote Darmo Grande and other 
large-scale real estate that emerged in the suburbs from the 1970s to a residential upper-class Chinese. They, according to Dick, prefer to live with other Chinese and avoid contact with villagers, slums, street vendors, and becak- p 397.

\section{Gating: the security aspect or lifestyle?}

Pakuwon City is located in east of Surabaya, Indonesia. It is a large scale residential development consists of 2694 unit houses took over land of 400 ha. It is one of the best residential for middle and high class of society in Surabaya. Location of case study is showed in Fig. 1.

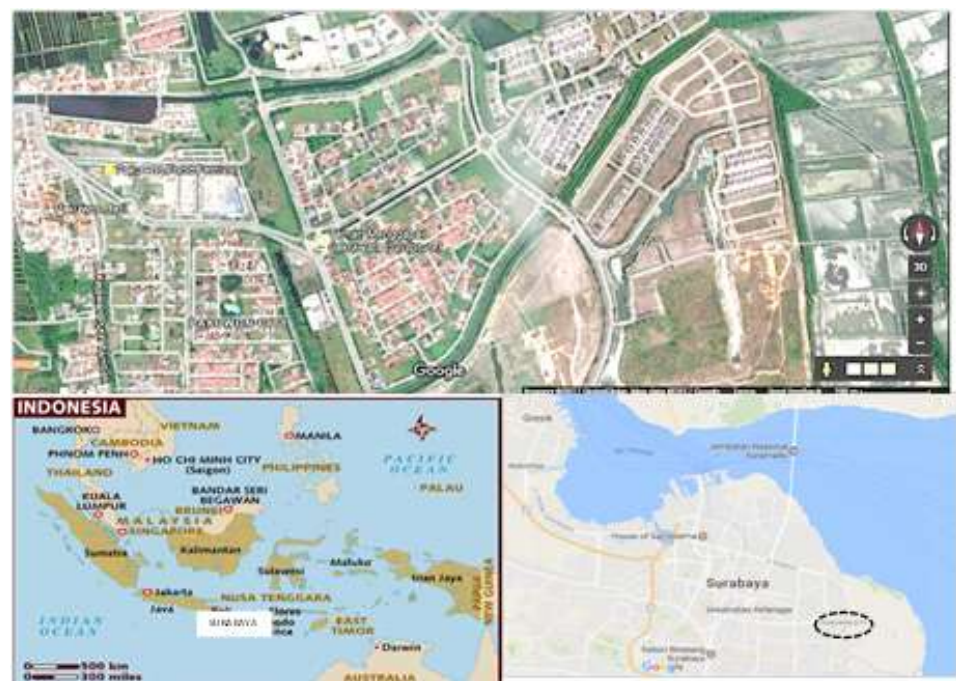

Figure 1. Location of Pakuwon City residential

The most interesting thing in GC design in Surabaya is that most of the residential (especially those above 500ha) are not pods or enclaves that are closed, as is common in the United States. Most GCs in the United States are exclusive residential that require visitors to be screened before entering the GC. In Surabaya, Pakuwon City, Galaxi Bumi Permai, and CitraLand to name the largest, can be easily reached via major roads and almost without a security check point at all. The residential main roads are connecting roads to another areas or short cuts that are used publicly for daily mobility. Pakuwon City main road connects this GC with Kenjeran area to the north, with Keputih disctict at south, and with the city center at west. No gate no fence no massive border at main entrance. This "open access GC" makes border functioned not to limit social mobility - in Sennet terms [3] (2008) to keep out! -but acting as entrance gate that is welcoming or inviting. While several gates in Pakuwon City that become a famous photo spots in Surabaya is showed in Fig. 2.
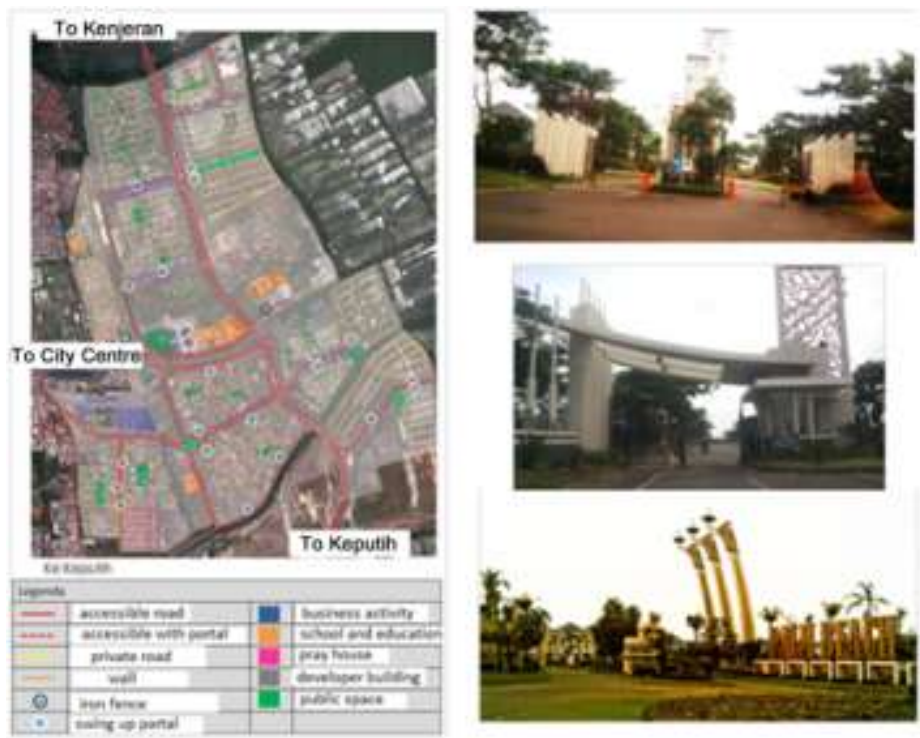

Figure 2. Accessible main road and welcoming gate in Pakuwon City 
Another interesting point is that the main road is populated by large and most expensive lots. The accessible main road has made this lots become more public and more open. With its "public" position, not all houses design a high fence or massive wall. Most of the houses design a semi-open fence with less than 2 meters height. It explains that even the block is open and most of the haves live here, fence and gate do not manifest as security aspect for protection.

Gating does not appear on the main entrance of GC as is often seen in the US, but rather on clusters or blocks deeper inside. Gating can be iron fencing driven by security officers, swing-up portals that are mechanically driven with access card or a combination of swing up portals and security officers. Multiple locations in Pakuwon City require non-resident visitors to leave their IDs before entering the cluster or block. Here gating is applied by swing up portal and access card so that only the residents can access the cluster (Figure 3).
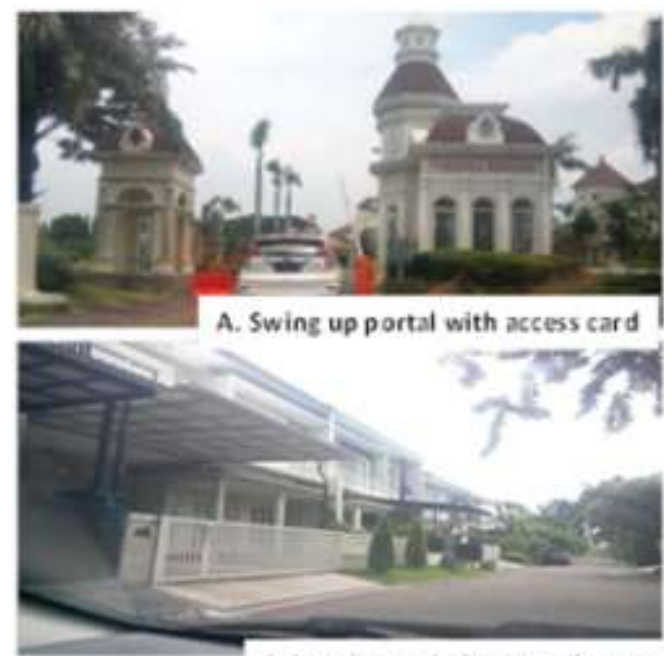

C. Low fences in housing clusters
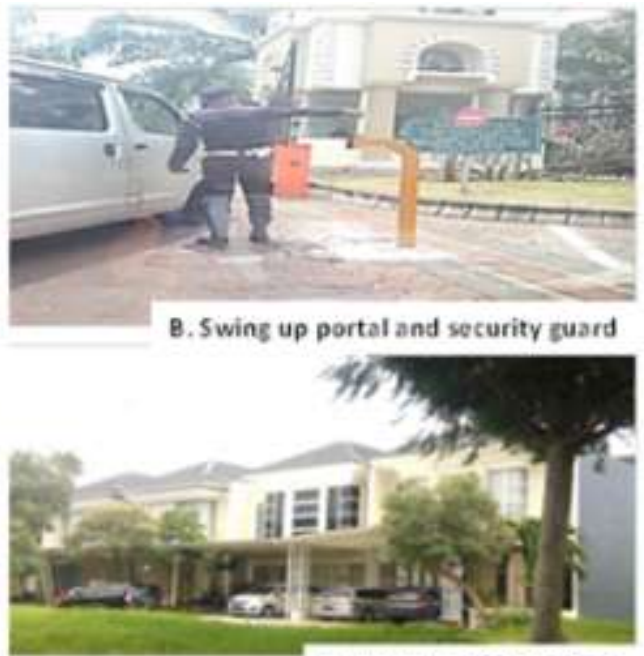

D. Cluster with no tences

Figure 3. Various gating features

After applying gating in all clusters, houses also equipped with fence. Another interesting situation occurs in the southern part of Pakuwon City where clusters are not only equipped with swing-up portals and security guards but are also fenced with a 3-meter hollow iron. It could be said that gating at cluster's main entrance is not enough so that residents need to fence their sub-clusters or houses too (Fig. 4). This is where gating appears to be manifestation of security aspect.

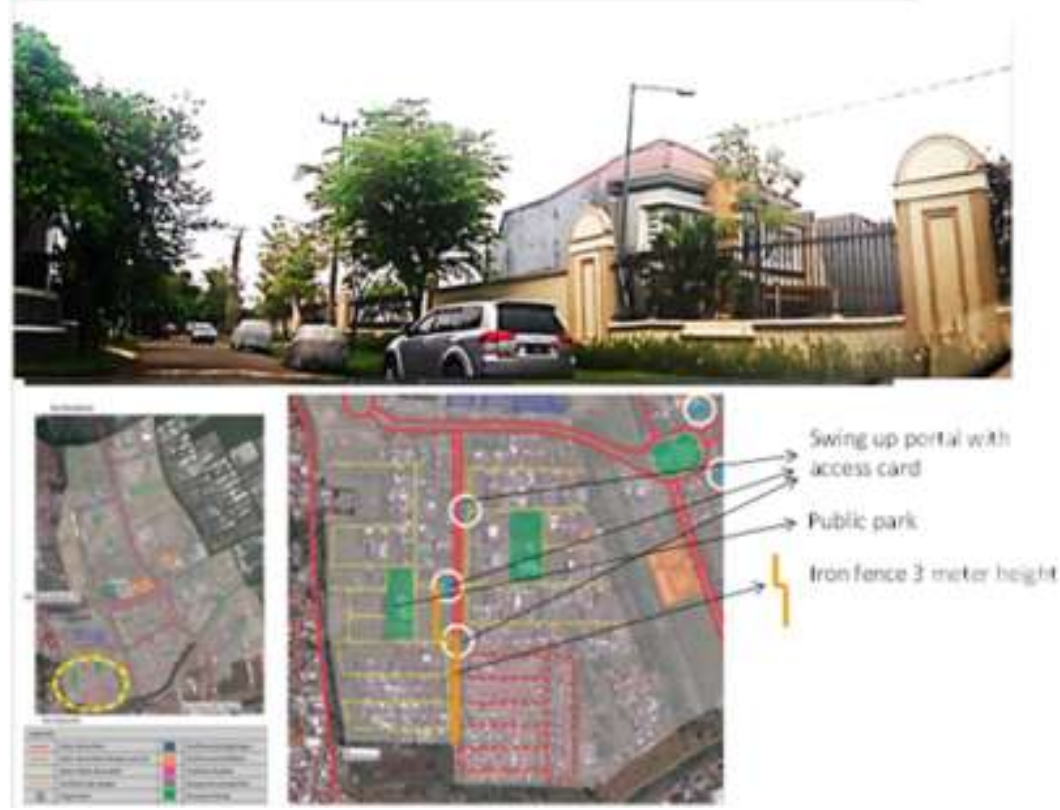

Figure 4. Gating inside cluster 
By looking at the variation of position, location, and design of gating elements above, it can be said that gating in Pakuwon City is a combination of manifestation of security aspect and lifestyle both. The security aspect can be seen from the security features that are designed on all clusters. This feature is ranging from simple iron fencing to swing up portal with access card. The gating creates sense of blocking too, as some public spaces such as parks and swimming pools built inside clusters.

\section{Segregation or not segregation?}

When compared to the phenomenon of gating in the United States, the situation in Pakuwon City shows a significant difference. The Pakuwon City case is not closed enclaves with one-gated system like mostly in US. Security features such as guard posts, iron gates, and swing up portals are built on GC clusters not on the main entrance. Thus one GC equipped dozens of security features depending on the number of clusters. Several clusters in Pakuwon City combine guard posts, swing up portals, and fences at once.

Segregation occurs because the position and location of gating often makes access to public spaces to be restricted. The residential layout in Pakuwon City should make it easier to reach certain places within a short distance. But, the use of gating at some point causes rotation for accessing places. Similarly, gating at a number of clusters where public spaces located, have been created segregation. We resume that if segregation is a condition where access to public functions is marginalized or restricted, it can be concluded that residential segregation has occurred in Pakuwon City. The spatial segregation that occurs within the GC separates clusters, NOT between residents of GC and non-GC. Since some parts of the GC can be accessed publicly while some other parts are separated, the segregation is not fully but semi-restricted (Fig. 5).

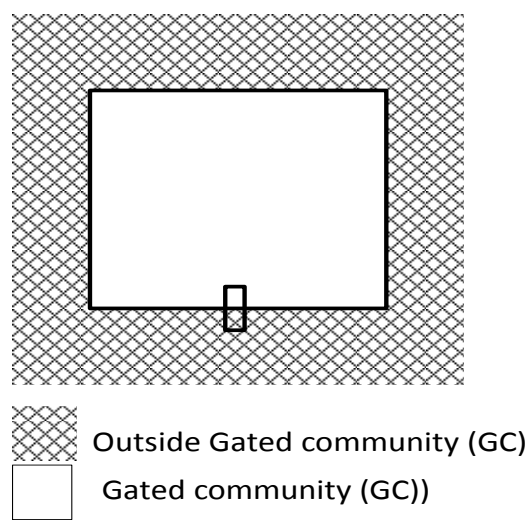

A. Fully segregation

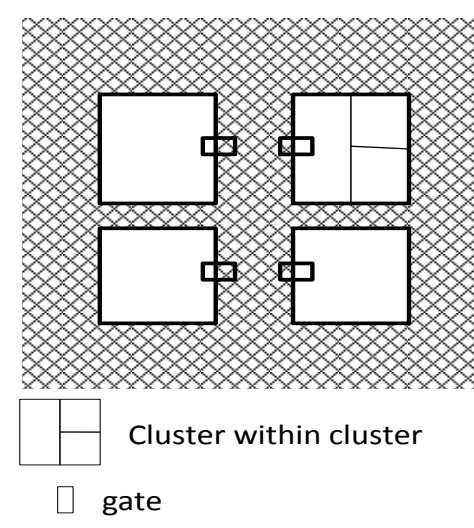

B. Semi-restricted segregation

Figure 5. Semi-restricted segregation

\section{CONCLUSION}

Segregation is defined as spatial dominance of a particular group in terms of income levels, race, religion, ethnicity, etc. By analyzing location, position, and design of gating elements, this paper concludes there is no spatial segregation occurs based on socioeconomic or racial class in Surabaya. The GC does not build gates or fences to separate the residency with its surroundings. Segregation occurs in the form of clusters inside the GC. On the one hand, the absence of gates and fences as well as appearance of accessibility of main entrance, shows the nature of openness.

On the other hand, all clusters are almost entirely provided with security features, blocking access to roads and public spaces, and therefore exhibit segregation. This is not intended to give a distinction in terms of socioeconomic status between residents, but rather as aspects of both security and life style. In contrast to studies in the United States that show the segregate nature due to the high restricted of GC, Pakuwon City exhibits a semirestricted nature of segregation. 


\section{REFERENCES}

[1] Atkinson, R., \& Blandy, S. (2005). Introduction: International perspectives on the new enclavism and the rise of gated communities. Housing Studies, 20(2), 177-186.

[2] Low, S. (2003). Behind the gates. New York and London: Routledge.

[3] Sennett, R. (2006). The open city. Urban age, 1-5.Atkinson, R., \& Flint, J. (2003). Fortress UK? Gated communities, the spatial revolt of the elites and time-space trajectories of segregation.

[4] Atkinson, R., \& Flint, J. (2003). Fortress UK? Gated communities, the spatial revolt of the elites and time-space trajectories of segregation.

[5] Douglass, M., Wissink, B., \& van Kempen, R. (2012). Enclave urbanism in China: Consequences and interpretations. Urban geography, 33(2), 167-182.

[6] Graham, S., \& Marvin, S. (2001). Splintering urbanism: networked infrastructures, technological mobilities and the urban condition. Psychology Press.

[7] Ellin, N. (1997). Architecture of fear. Princeton Architectural Press.

[8] Caldeira, T.P.R. (2000). City of Walls: Crime, Segregation and Citizenship in São Paulo. University of California Press.

[9] Blakely, E. J., \& Snyder, M. G. (1997). Divided we fall: Gated and walled communities in the United States. Architecture of fear, 8599.

[10] Leisch, H. (2002). Gated communities in Indonesia. Cities, 19(5), 341-350.

[11] Schnell, I., Diab, A. A. B., \& Benenson, I. (2015). A global index for measuring socio-spatial segregation versus integration. Applied Geography, 58, 179-188.

[12] Marcuse, P. (1997). Walls of fear and walls of support. Architecture of fear, 101-114.

[13] Ellin, N. (2001). Thresholds of fear: embracing the urban shadow. Urban studies, 38(5-6), 869-883.

[14] Bickford, S. (2000). Constructing inequality: City spaces and the architecture of citizenship. Political Theory, 28(3), 355-376.

[15] Grant, J., \& Mittelsteadt, L. (2004). Types of gated communities. Environment and Planning B: Planning and Design, 31(6), 913930.

[16] Johnson, C., Jones, R., Paasi, A., Amoore, L., Mountz, A., Salter, M., \& Rumford, C. (2011). Interventions on rethinking 'the border'in border studies. Political Geography, 30(2), 61-69.

[17] Glebbeek, M. L., \& Koonings, K. (2016). Between Morro and Asfalto. Violence, insecurity and socio-spatial segregation in Latin American cities. Habitat International, 54, 3-9.

[18] Massey, D. S., \& Denton, N. A. (1988). The dimensions of residential segregation. Social forces, 67(2), $281-315$.

[19] Firman, T. (2004). New town development in Jakarta Metropolitan Region: a perspective of spatial segregation. Habitat International, 28(3), 349-368.

[20] Winarso, H., Hudalah, D., \& Firman, T. (2015). Peri-urban transformation in the Jakarta metropolitan area. Habitat International, 49, 221-229.

[21] Hillir, B. \& J. Hanson. (1984) The Socio Logic of Space. Cambridge: Cambridge University Press

[22] Ginting, S. W., Darjosanjoto, E. T., \& Sulistyarso, H. (2017, March). Can Architecture Design Solve Social Problem?. In IOP Conference Series: Materials Science and Engineering (Vol. 180, No. 1, p. 012082). IOP Publishing.

[23] Rakodi, C., \& Firman, T. (2009). Planning for an Extended Metropolitan Region in Asia: Jakarta, Indonesia. Case study prepared for Revisiting Urban Planning: Global Report on Human Settlements.

[24] Nas, P. J. (2003). The Indonesian town revisited (Vol. 1). LIT Verlag Münster.

[25] Dick, H. (2002). Surabaya: City of Work. Ohio University Press. 